\title{
Reação de genótipos de soja ao nematóide reniforme
}

\author{
Guilherme Lafourcade Asmus
}

Embrapa Agropecuária Oeste, Cx. Postal 661, 79804-970 Dourados, MS, Brasil, e-mail: asmus@cpao.embrapa.br

RESUMO

Trinta e um genótipos de soja, incluindo cultivares recomendadas no norte de MS, sul de MT ou no Triângulo Mineiro e linhagens promissoras do programa de melhoramento genético de soja da Embrapa e os padrões de resistência ('Custer') e de suscetibilidade ('BR 9625619') foram avaliadas quanto à reação ao nematóide reniforme em casa-de-vegetação da Embrapa Agropecuária Oeste, em Dourados, MS. Plantas de cada genótipo foram inoculadas individualmente com 1.000 ovos e formas larvais de Rotylenchulus reniformis. Aos 60 dias após a inoculação, os nematóides foram extraídos das raízes e do solo, e estimaram-se os fatores de reprodução (FR) e os números de nematóides por grama de raiz. As cultivares BRSMG 250 [Nobreza], TMG115RR, TMG121RR, TMG113RR, BRS Jiripoca e M-SOY 8336RR e mais a linhagem MGBR01-5849 apresentaram FR e número de nematóides/g de raiz estatisticamente semelhantes ao padrão de resistência 'Custer'. A maioria destas cultivares já havia sido relatada como resistente ao nematóide de cisto da soja (NCS), indicando a possibilidade de direcionar-se a busca por cultivares de soja resistentes ao nematóide reniforme, pela avaliação preferencial de cultivares resistentes ao NCS.

Palavras-chave: Rotylenchulus reniformis, Glycine max, resistência, controle.

\begin{abstract}
Reaction of soybean genotypes to the reniform nematode

Thirty-one selected soybean genotypes including cultivars and breeding lines developed for the north of Mato Grosso do Sul, south of Mato Grosso, and the "Triângulo Mineiro" region of Minas Gerais states, Brazil, were evaluated for resistance to Rotylenchulus reniformis in a greenhouse experiment. Plants of each cultivar were individually inoculated with 1,000 eggs and vermiform Rotylenchulus reniformis nematodes. The reproduction factor (RF) and the number of $R$. reniformis/g of roots were calculated for each cultivar 60 days after inoculation. The cultivars BRSMG 250 [Nobreza], TMG115RR, TMG121RR, MGBR015849, TMG113RR, BRS Jiripoca, and M-SOY 833RR gave values of RF and number of nematodes/g root that did not differ statistically from those for the known resistant cultivar 'Custer'. Most of these cultivars are resistant to the soybean cyst nematode ( $\mathrm{SCN}$ ) as well, indicating that the identification of cultivars that can be recommended as resistant to the reniform nematode would be accelerated by giving first priority to the evaluation of SCN-resistant cultivars.
\end{abstract}

Keywords: Rotylenchulus reniformis, Glycine max, resistance, control.

O nematóide reniforme, Rotylenchulus reniformis Lindford \& Oliveira 1940, é um importante parasita de várias culturas de interesse econômico (Robinson et al, 1997). Até o início da atual década, $R$. reniformis foi considerado um patógeno secundário para a soja. Entretanto, sua ocorrência tem aumentado de forma consistente nos últimos anos, principalmente no Estado de Mato Grosso do Sul (Asmus, 2005). Constitui em emergente problema fitossanitário às lavouras de soja daquele Estado, onde altas populações do nematóide têm sido associadas a perdas em rendimentos na cultura (Asmus et al., 2003).

Há fontes de resistência conhecidas ao nematóide reniforme no germoplasma de soja (Robbins et al., 2002). Destacam as cultivares norte-americanas Forrest e Custer, consideradas padrões de resistência ao nematóide. Ao avaliarem a reação de cultivares e linhagens de soja ao nematóide de cisto da soja (Heterodera glycines) e ao nematóide reniforme, Robbins \& Rakes (1996) observaram que, à exceção da PI 88788, as fontes de resistência ao nematóide de cisto também conferiram resistência a $R$. reniformis. Asmus \& Schirmann (2004) avaliando algumas cultivares comerciais de soja indicadas em Mato Grosso do Sul, verificaram que 'M-SOY 8001' e 'CD 201' foram as mais resistentes ao nematóide reniforme. No entanto, estas cultivares não são bem adaptadas para cultivo no Centro-Norte do Estado, onde o referido nematóide também já passa a ser problema. Este fato, aliado ao extremo dinamismo dos programas de melhoramento de soja, com lançamentos de diversas novas cultivares a cada ano, cria a necessidade de avaliações contínuas da reação de tais cultivares ao nematóide reniforme. Desta forma, decidiu-se avaliar a reação de um grupo adicional de genótipos de soja. $\mathrm{O}$ experimento foi conduzido em casa-de-vegetação da Embrapa Agropecuária Oeste, em Dourados MS, no período de 16/05/06 a 31/07/06.

Sementes pré-germinadas de cultivares adaptadas às regiões Norte de MS, Sul de MT e Triângulo Mineiro, e de linhagens promissoras dos programas de melhoramento de soja da Embrapa e dos padrões de resistência ('Custer') e suscetibilidade ('BR 9625619') foram transplantadas, individualmente, para copos de polietileno, com capacidade para $500 \mathrm{~mL}$, contendo mistura 1:1 (v/ v) de solo e areia lavada, desinfestada com brometo de metila (150 $\mathrm{mL} \mathrm{m}^{-3}$ ). Dois dias após o transplantio, cada planta foi inoculada com $5 \mathrm{~mL}$ de uma suspensão aquosa contendo 1.000 ovos e formas larvais de uma população de $R$. reniformis obtida de raízes de soja oriunda do município de Maracaju, MS, e multiplicada, por 90 dias, em raízes de maracujazeiro. Para obtenção do inóculo, as raízes de maracujazeiro foram trituradas, em liquidificador, e a suspensão resultante clarificada, por centrifugação (Collen \& D’Herde, 1972). O inóculo foi depositado em dois orifícios de 
aproximadamente $3 \mathrm{~cm}$ de profundidade, distantes $1 \mathrm{~cm}$ do colo das plantas de soja.

Sessenta dias após a inoculação foram quantificados o número de nematóides no solo (Jenkins, 1964) e nas raízes da soja (Collen \& D'Herde, 1972), em cada vaso, e determinado o peso fresco das raízes. Os dados obtidos foram utilizados para estimar o número de nematóides (ovos e formas larvais) por grama de raiz e o fator de reprodução (FR) do parasita em cada genótipo de soja. Para a obtenção do FR foi utilizada a expressão:

$\mathrm{FR}=$ População final do nematóide nas raízes e no solo População inicial do nematóide (inóculo $=1.000$ )

$\mathrm{O}$ delineamento experimental foi $\mathrm{o}$ inteiramente casualizado, com cinco repetições. Cada copo contendo uma planta de soja constituiu-se numa parcela. Para a análise estatística, os dados da estimativa do número de nematóides por grama de raiz foram transformados em $\sqrt{x \quad 0,5}$. As médias dos tratamentos foram comparadas pelo teste de Scott-Knott $(\mathrm{p}<0,05)$.

Os resultados obtidos evidenciaram haver grande variação na reação dos genótipos de soja ao nematóide reniforme (Tabela 1). Ao ser considerada a variável fator de reprodução, um grupo de seis cultivares (BRSMG 250 [Nobreza], TMG115 RR, TMG121 RR, TMG113 RR, BRS Jiripoca e M-SOY 8336 RR e a linhagem MGBR01-5849) foi estatisticamente semelhante ao padrão de resistência 'Custer'. Quando considerado o número de nematóides por grama de raiz, também incluiram-se nesse grupo as cultivares BRS Valiosa RR e BRS Invernada. Um número expressivo de cultivares

TABELA 1 - Fatores de reprodução (FR) de Rotylenchulus reniformis e números de nematóides por grama de raiz em genótipos de soja após 60 dias de inoculação com 1.000 ovos e formas larvais, em casa-de-vegetação

\begin{tabular}{|c|c|c|}
\hline GENÓTIPOS & FR & Nematóides/g de raiz \\
\hline CD 222 & $5,68 \mathrm{a}^{(1)}$ & $23,23 \mathrm{~b}$ \\
\hline BR 02-62965RR & $5,45 \mathrm{a}$ & $60,13 \mathrm{a}$ \\
\hline BR 01-66633RR & $5,01 \mathrm{a}$ & $51,29 \mathrm{a}$ \\
\hline BR 00-13279 & $3,76 \mathrm{~b}$ & $22,88 \mathrm{~b}$ \\
\hline CD 204 & $3,39 \mathrm{~b}$ & $48,89 \mathrm{a}$ \\
\hline BRS Favorita RR & $3,28 \mathrm{~b}$ & $78,69 \mathrm{a}$ \\
\hline CD 219RR & $3,17 \mathrm{~b}$ & $21,00 \mathrm{~b}$ \\
\hline CD 217 & $2,91 \mathrm{~b}$ & $21,73 \mathrm{~b}$ \\
\hline BRS 245RR & $2,43 \mathrm{c}$ & $23,53 \mathrm{~b}$ \\
\hline BR 96-25619 (Padrão de suscetibilidade) & $1,68 \mathrm{c}$ & $23,38 \mathrm{~b}$ \\
\hline BRS 244RR & $1,62 \mathrm{c}$ & $13,59 \mathrm{c}$ \\
\hline BRS 247RR & $1,61 \mathrm{c}$ & $16,75 \mathrm{c}$ \\
\hline BRS Charrua RR & $1,54 \mathrm{c}$ & $32,71 \mathrm{~b}$ \\
\hline MG/BR 46 Conquista & $1,27 \mathrm{~d}$ & $9,84 \mathrm{c}$ \\
\hline BRSMG Garantia & $1,21 \mathrm{~d}$ & $15,05 \mathrm{c}$ \\
\hline BR 02-73050RR & $1,19 \mathrm{~d}$ & $11,60 \mathrm{c}$ \\
\hline TMG117RR & $1,17 \mathrm{~d}$ & $5,89 \mathrm{c}$ \\
\hline BR 02-64301RR & $1,12 \mathrm{~d}$ & $36,14 \mathrm{c}$ \\
\hline BRS Invernada & $1,04 \mathrm{~d}$ & $1,63 \mathrm{~d}$ \\
\hline BRSMG 251 Robusta & $1,00 \mathrm{~d}$ & $21,07 \mathrm{c}$ \\
\hline BRSMG 68 Vencedora & $0,90 \mathrm{~d}$ & $9,10 \mathrm{c}$ \\
\hline MGBR 01-71210 RR & $0,89 \mathrm{~d}$ & $11,45 \mathrm{c}$ \\
\hline BRS Valiosa RR & $0,87 \mathrm{~d}$ & $12,86 \mathrm{~d}$ \\
\hline Custer (Padrão de resistência) & $0,42 \mathrm{e}$ & $5,11 \mathrm{~d}$ \\
\hline M-SOY 8336RR & $0,38 \mathrm{e}$ & $2,72 \mathrm{~d}$ \\
\hline BRS Jiripoca & $0,35 \mathrm{e}$ & $3,61 \mathrm{~d}$ \\
\hline TMG113RR & $0,33 \mathrm{e}$ & $2,03 \mathrm{~d}$ \\
\hline MGBR 015849 & $0,31 \mathrm{e}$ & $1,05 \mathrm{~d}$ \\
\hline TMG121RR & $0,30 \mathrm{e}$ & $2,67 \mathrm{~d}$ \\
\hline TMG115RR & $0,24 \mathrm{e}$ & $3,11 \mathrm{~d}$ \\
\hline BRSMG 250 [Nobreza] & $0,13 \mathrm{e}$ & $1,10 \mathrm{~d}$ \\
\hline Quadrado médio & 11,9093 & 347,7884 \\
\hline $\mathrm{F}$ & $25,07 * *$ & $14,43 * *$ \\
\hline C.V. $(\%)$ & 39,10 & 26,75 \\
\hline
\end{tabular}


permitiu multiplicação maior que o padrão de suscetibilidade ('BRS 96-25619').

Com exceção de BRS Valiosa RR e de BRSMG 68 [Vencedora], todas as cultivares que mostraram resistência ao nematóide reniforme $(\mathrm{FR}<1,0)$ também são resistentes às raças 3 ou 1 e 3 do o nematóide de cisto da soja (NCS), como previsto por Robbins \& Rakes (1996). Por outro lado, a cultivar CD 217, que tem como fonte de resistência à raça 3 do NCS a PI 90763, foi suscetível ao nematóide reniforme, constituindose em exceção.

Até o momento, o programa de melhoramento da soja para o Centro-Sul de MS não se preocupou com a busca de genótipos resistentes ao NCS, visto que este nematóide ainda não foi detectado na Região (Dias et al., 2006). Este fato pode explicar o baixo número de cultivares indicadas para a Região com resistência ao nematóide reniforme (Asmus \& Schirmann, 2004). Para abreviar o tempo para a recomendação de cultivares resistentes ao nematóide reniforme, sugere-se concentrar prioritariamente os estudos naqueles genótipos que apresentem comprovada resistência ao nematóide de cisto da soja.

\section{REFERÊNCIAS BIBLIOGRÁFICAS}

Asmus GL (2005) Evolução da ocorrência de Rotylenchulus reniformis em Mato Grosso do Sul, durante o quinquênio
2001/2005. Resumos, 27a . Reunião de Pesquisa de Soja da Região Central do Brasil. Cornélio Procópio PR. pp. 221-222.

Asmus GL, Schirmann MR (2004) Reação de cultivares de soja recomendadas no Mato Grosso do Sul ao nematóide reniforme. Nematologia Brasileira 28:239-240.

Asmus GL, Rodrigues E, Isenberg K (2003) Danos em soja e algodão associados ao nematóide reniforme (Rotilenchulus reniformis) em Mato Grosso do Sul. Nematologia Brasileira 27:267.

Coolen WA, D'Herde CJA (1972) Method for the quantitative extraction of nematodes from plant tissue. Ghent, Belgium. State Nematology and Entomology Research Station.

Dias WP, Silva JFV, Garcia A (2006) Nematóides de importância para a soja no Brasil. In: Suzuki S, Yuyama MM, Camacho SA (Eds) Boletim de pesquisa de soja. Rondonópolis MT. Fundação Mato Grosso. pp. 139-151.

Jenkins WR (1964) A rapid centrifugal-flotation technique for separating nematodes from soil. Plant Disease Reporter 48:692.

Robbins RT, Rakes, L (1996) Resistance to the reniform nematode in selected soybean cultivars and germplasm lines. Journal of Nematology 28:612-615.

Robbins RT, Shipe ER, Rakes L, Jackson LE, Gbur EE, Dombek DG (2002) Host suitability of soybean cultivars and breeding lines to reniform nematodes in tests conducted in 2001. Journal of Nematology 24:378-383.

Robinson AF, Inserra RN, Caswell-Chen EP, Vovlas N, Troccoli A (1997) Rotylenchulus species: identification, distribution, host ranges, and crop plant resistance. Nematropica 27:127-180.

Recebido 9 Agosto 2007 - Aceito 29 Janeiro 2008 - TPP 7087 Editor Associado: Ricardo M. Souza 